\title{
On the Application of Dongui Bogam for the Memory of the World Register: Influences and Reflections
}

\author{
Diangang Liu \\ School of Foreign Languages \\ Hubei University of TCM \\ Wuhan City, Hubei Province, 430065, PRC \\ liudiangang@163.com \\ Herong Mao \\ School of Foreign Languages \\ Hubei University of TCM \\ Wuhan City, Hubei Province, 430065, PRC \\ trans_morning123@126.com
}

\author{
Chi Gu* \\ School of Foreign Languages \\ Hubei University of TCM \\ Wuhan City, Hubei Province, 430065, PRC \\ guchihbtcm@163.com \\ Yunhui Wu \\ School of Foreign Languages \\ Hubei University of TCM \\ Wuhan City, Hubei Province, 430065, PRC
}

\begin{abstract}
Dongui Bogam, the Korean medical classic, has been deeply rooted in traditional Chinese culture, especially traditional Chinese medical culture. Its application for the Memory of the World Register has triggered heated discussion internationally on cultural consciousness and cultural protection etc. We strongly believe that the application event has exerted profound influence on the South Korean cultural confidence and cultural self-consciousness as well as the reflection on the protection of Chinese cultural sovereignty, and there are a few valuable lessons we should learn from the event.
\end{abstract}

Keywords-Dongui Bogam; application for the Memory of the World Register; influences; reflections

\section{INTRODUCTION}

In the late 16th and early 17th century, people of ancient Korea were suffering from stricken-poverty and severe pestilence because Korea at that time was a war-ravaged country composed of a couple of states. The King then Joseon Seonjo was pitiful of people's suffering and placed great hope on medicine, so he instructed the great royal doctors to compile an encyclopedic work of medicine. Heo Jun and other literati spent 15 years under the king's decree compiling the medical classic. They finally completed the compilation work Principles and Practice of Eastern Medicine or Dongui Bogam (translated from Korean language) in 1610 A.D [1]. Right after the advent, the classic had been taken seriously by all the governments of ancient Korea and later the South Korean government.

Obviously, this medical classic had been deeply influenced by traditional Chinese medicine (TCM) and traditional Chinese culture. It has referred to many TCM classics, such as the Plain Questions, the Spiritual Pivot, and Treatise on Exogenous Febrile Diseases. The essence of the classic is to disclose the nature of medicine by studying the circulation of

This research is financially supported by academic programs of Hubei provincial department of education (2014318，15Q112 )
Qi and Blood, differentiation of four manifestations (Si Xiang) and mutual promoting and restraining of the Five Elements. What's more, Taoism, Confucianism and Buddhist beliefs have all exerted profound influence on the compilation of the classic [2]

With great efforts made by the Cultural Heritage Administration of the Republic of Korea, the two full sets of the first print of Dongui Bogam was successfully registered on the Memory of the World List by the United Nations Educational, Scientific and Cultural Organization (the UNESCO) on July 31, 2009. The successful application of the classic has stirred up heated discussion both at home and abroad, especially in China, where it is generally believed to be the hometown of all traditional Chinese medicine.

\section{INFLUENCES OF THE APPLICATION OF DONGUI BOGAM} FOR THE MEMORY OF THE WORLD REGISTER

\section{A. Influence on the South Korean Cultural Confidence and Cultural Self-consciousness}

Dongui Bogam's successful application for the Memory of the World Register has received worldwide attention. It had been a bridge for the spread of traditional Korean medical culture and had received a well-known reputation throughout the world. The year of 2013 marked the 400th anniversary of the publication of Dongui Bogam. So in this year, the South Korean government had set up a commission on the promotion of the work for preparing the inscription, carrying out the editing of a new version and other relevant works. At the same time, more and more foreigners are going to South Korea to study traditional Korean medicine from then on, which further enhances the South Korean confidence on the cultural legacies left by their ancestors.

Dongui Bogam's successful application for the Memory of the World Register has also improved the cultural self- 
consciousness for different groups of interests in South Korea. Since the application, the South Korean government has paid much more attention to protecting its traditional culture to make it more popular and internationalized. However, it's generally held that the South Korean traditional culture is profoundly rooted in Confucianism. On the basis of this rich background, it did not only actively absorb the essence of western culture, but also made creative transformation of their traditional culture. Thus a model of Korean modern culture with distinctive features of the times was formed. By combining the excellent traditional culture with modern fashion trends, South Korea has created a modern culture with Korean characteristics and successfully made it more popular and famous on the international arena. As some South Korean scholars believed, traditional Korean culture will continue to survive only by closely connecting and constantly updating with the times [3].

Unlike China, South Korea doesn't have long prosperous history as well as the magnificent landscapes. But it has far surpassed China in the protection of culture and greater efforts can be clearly seen after the successful application [4]. For instance, at the end of 2013, Kim Chi was recognized by the UNESCO under the continuous promotion of South Korean government. Finally, Pickles and Kim Chi were registered on the World Intangible Cultural Heritage List. In 2015, the Tugof-war across four countries of South Korea, Vietnam, Cambodia and the Philippines was included in UNESCO's List of Intangible Cultural Heritage. And by then, Tug-of-war has become the 18th National Intangible Cultural Heritage in South Korea. The accomplishments South Korea has made in cultural protection truly manifest South Korean selfconsciousness of traditional cultural values and the international recognition of South Korean traditional culture all over the world.

\section{B. Influence on the Protection of Chinese Cultural Sovereignty}

Since 2009, Chinese government has issued a series of policies in the protection of TCM culture. In 2009, the State Council had issued a document, Opinions on Supporting and Promoting the Development of TCM Cause, which clearly states that TCM with its profound philosophical thoughts and humanities is our national treasure and the representative of the soft power of our country, and that TCM has played an important role in promoting the development of traditional Chinese culture on the whole.

In terms of the world cultural heritage application of TCM, the Chinese government had also changed its strategy from taking TCM as a whole to dividing TCM into individual parts. It's requested that when applying for the world cultural heritage we should give details of each item as concrete as possible. The successful application of Acupuncture and Moxibustion was the very fruit of this policy's adjustment. On November 16, 2010, Traditional Chinese Acupuncture and Moxibustion were inscribed on the List of Intangible Cultural Heritage of Mankind by UNESCO. This success prevents the further alienation and desensitization of acupuncture and moxibustion and has laid a foundation for TCM's international transmission in the future [5].

\section{REFLECTIONS ON THE APPLICATION OF DONGUI BOGAM FOR THE MEMORY OF THE WORLD REGISTER}

Except for its value in the inheritance and development of TCM classics, Dongui Bogam also attaches great significance to the study of the integrity of TCM classics due to its wide collection of TCM classics in history. For example, it had preserved some lost articles of TCM classics in the early history, such as the lost parts of Zhang Zhongjing's and Ge Hong's medical works. In this sense, it is of great literature value in reediting some significant TCM classics. That's the very important reason why its successful application has got so many Chinese people so nervous. Then, what lessons can we learn from the event?

The rapid development of traditional Korean medicine has a lot to do with the government's protecting and exploiting policies in traditional medicine or even in traditional culture. The South Korean government has a unique model of cultivating traditional Korean medicine talents. For example, being a traditional Korean medicine doctor is a popular profession now in South Korea. If one wants to study traditional Korean medicine, he is required to gain high scores in the entrance examination. He has to study in the university for six years, with two years of pre-medical education and four years of undergraduate education, which reflects the management system of a combination of credit system and grading system. To be a traditional Korean medicine practitioner, one must take the relevant tests [6]. The South Korean government does not accept the students who get relevant qualification or degrees abroad. When returning home, one still has to study at the Korean medical university and attend the relevant examination for the qualifications of being doctors.

The South Korean government has developed a flexible management policy of developing traditional Korean medicine too. Early in 1951, the government had promulgated relevant laws that identified the equal position of traditional Korean medicine and Western Medicine, which has laid one of the foundations for the rapid development of traditional Korean medicine [7].

Additionally, the South Korean government attaches great importance to cultivating the public's awareness and educating the traditional culture. The government and the public have taken active measures to protect traditional culture. For example, a small pottery-kiln site, an ancient wall, or a temple might be the tangible treasure in South Korea. In many museums and memorial halls, we can see many young parents came to visit with their children. They patiently talk to their children about South Korean cultural relics, which prove to be a great cultural enlightenment for the generations to come.

All in all, the protection and development of traditional culture are inseparable from the government's efforts and policies, but more importantly they are connected with the cultural consciousness of the ordinary people in South Korea. We have a lot to learn from Dongui Bogam's applying for the Memory of the World Register.

Also, we should learn something from the application about how to improve the soft power of our country. TCM is 
an important manifestation of the soft power of our country. So how to increase the soft power of traditional culture by improving the soft power of TCM has been a heated topic.

Firstly, we should strengthen the construction of the Confucius Institute of Traditional Chinese Medicine to promote the soft power of Traditional Chinese Medicine. The Confucius Institute of TCM, an institution for spreading and promoting Traditional Chinese Medicine, has still a long way to go in promoting the soft power of traditional Chinese medicine. The foundation of the Confucius institute of traditional Chinese medicine is the innovation force. It is the bridge to carry forward and promote traditional Chinese medicine culture which has made tremendous contributions to the spread of traditional Chinese medicine. And it is an important way to promote soft power of TCM culture.

Secondly, we should actively publicize and promote the culture of traditional Chinese medicine and strengthen the communication and dissemination of Traditional Chinese Medicine culture. The following steps should be taken to realize the spread of TCM culture.

On the one hand, making full use of the public platforms such as high-level national visits and academic exchanges. In 2009, President Hu Jintao gave a book Twenty-four Histories to the national library of Turkmenistan, which further ignited the local people's enthusiasm on learning Chinese.

On the other hand, combining with the use of modern technology to disseminate Traditional Chinese Medicine culture. The advanced science and technology should be effectively utilized. We can represent TCM culture in the form of text, sound, image, video, animation, etc. I believe that it is a good idea to write a multilingual story about the famous physicians in history, or to make multilingual movies or TV series with the celebrities or medical books as the model prototype.

\section{CONCLUSION}

Dongui Bogam is mainly compiled with Chinese characters, which is divided into five categories: Naegyeong (Overview of the Inner Body), Oehyeong (External Appearance), Japbyeong (Various Diseases), Tang-aek (Liquid Medications) and Acupuncture. The whole classic is totally made up of 104 items, including the etiology of various diseases, the syndromes, the drugs and the meridians, the acupuncture and moxibustion. In terms of types and frequency of the reference books, it includes Taoist books, history books, almanacks, Confucian classics and 83 medical books. Apparently, this classic has absorbed too much nutrition from traditional Chinese culture, especially traditional Chinese medical culture. In this sense, whether Dongui Bogam is a separate cultural entity remains controversial to date.

As China's former Vice-premier Liu Yandong stated, traditional Chinese medicine has become a unique health resource, an economic resource with huge potential, a scientific and technological resource with its original advantage, and an important ecological resource of our country. So the joint efforts should be made by the government, the public and us individuals to better develop traditional Chinese medicine at home and more widely spread traditional Chinese medicine to the rest of the world.

\section{ACKNOWLEDGMENTS}

This research is financially supported by academic programs of Hubei provincial department of education (2014318, 15Q112). Sincere thanks also go to colleagues from the Center for Compilation, Translation and International Communication of Jingchu TCM Literatures for their constructive suggestions in the writing of the paper.

\section{REFERENCES}

[1] UNESCO, Dongui Bogam, Principles and Practice of Eastern Medicine, 2009.

[2] Zhu Jianping, Heo Jun and Dongui Bogam, Chinese Journal of Basic Medicine in Traditional Chinese Medicine,2009,vol.1, pp.11-12.(In Chinese)

[3] Gunjoo Jang Won K. Paik, Korean Wave as Tool for Korea's New Cultural Diplomacy, Advances in Applied Sociology, 2012,vol. 2, p.3.

[4] Hee Young Kim, Hyung Woo Kim, Han Chae, Gi Young Yang, Sang Yun Han, Jung Haw Lim, Jin Hong Cheon, Young Kyu Kwon, The Past, Present and Future of Traditional Medicine Education in Korea, Integrative Medicine Research, 2016, vol. 5, 02, pp.73-82.

[5] Application of Acupuncture and Moxibustion for the World Cultural Heritage,http://newpaper.dahe.cn/hnsb/html/201009/14/content_383849. htm.(In Chinese)

[6] Hyun-Ji Lee, Han Chae, Young-Kyu Lim, Young-Kyu Kwon, Attitudes of Korean and Chinese Traditional Medical Doctors on Education of East Asian Traditional Medicine, Integrative Medicine Research, 2016 5 (1) , pp.63-68.

[7] Liu Yanling, What Should We Learn from Traditional Korean Medicine? Health News,2007-10-25(007).(In Chinese) 